\title{
Chapter 12 \\ The IMO Regulatory Framework for Arctic Shipping: Risk Perspectives and Goal-Based Pathways
}

\author{
Anish Arvind Hebbar, Jens-Uwe Schröder-Hinrichs, Maximo Q. Mejia, \\ Heike Deggim, and Sascha Pristrom
}

\begin{abstract}
The International Maritime Organization (IMO), in its capacity as a specialized agency of the United Nations, is the global regulator to ensure safety, security, environmental standards, efficiency and sustainability of international shipping. The current regulatory framework of IMO, which is developed and maintained on a continuous basis, includes over 50 international instruments and numerous codes, guidelines and circulars that cover every aspect of international shipping ranging from design, construction, equipment, manning and operation to ship recycling. The safety net of the universally adopted IMO regulations currently covers approximately 1.5 million seafarers and more than 60,000 ships. With declining ice cover leading to an increasing spiral of traffic despite the many hazards, safety of shipping in polar waters and, in particular, the Arctic and its fragile environment is a current focus area of IMO and purported to be addressed by the Organization through a set of goal-based regulatory standards. This chapter provides an overview of the IMO framework and process of shipping regulation and maps the transition from prescriptive to goal-based approach. Risk-based approaches to safety are discussed in the context of the Canadian Arctic. The chapter further reviews the IMO instruments relevant to the Arctic, including the Polar Code, and discusses the approaches to implementation at the flag state, coastal state and regional level, lending new insights and future pathways on tiered implementation of the IMO goal-based framework.
\end{abstract}

\footnotetext{
A. A. Hebbar $(\varangle) \cdot$ J.-U. Schröder-Hinrichs · M. Q. Mejia

World Maritime University, Malmö, Sweden

e-mail: ah@wmu.se; jus@wmu.se; max.mejia@wmu.se

H. Deggim

Maritime Safety Division, International Maritime Organization, London, UK

e-mail: hdeggim@imo.org

S. Pristrom

Marine Technology Section, International Maritime Organization, London, UK

e-mail: spristro@imo.org
} 
Keywords Arctic · Canada - Goal-based standards (GBS) - Goal-based standardssafety level approach (GBS-SLA) • International Maritime Organization (IMO) • IMO regulation · IMO regulatory framework $\cdot$ Maritime safety $\cdot$ Polar Code $\cdot$ Risk - Shipping

\subsection{Introduction}

The Arctic is uniquely distinctive in nature owing to its extreme milieu of low temperatures, high geographic latitude, the special magnetic phenomena and extraordinary light conditions. The many hazards of polar shipping, especially in the remote Arctic regions (Fig. 12.1), are perhaps without any parallel. In terms of meteorology, the Arctic is among the world's most poorly observed regions. Environmental conditions are generally quite harsh. Ice cover is variable and dynamic, and climate change is expected to have even further impacts. Bathymetric information is scant or outdated, and navigational chart information is not available for all polar waters. For example, only $10 \%$ of the Canadian Arctic is charted, and less than $25 \%$ of the charts are deemed to be of an adequate standard. Infrastructure to support ships in transit in terms of aids to navigation or ports and reception and

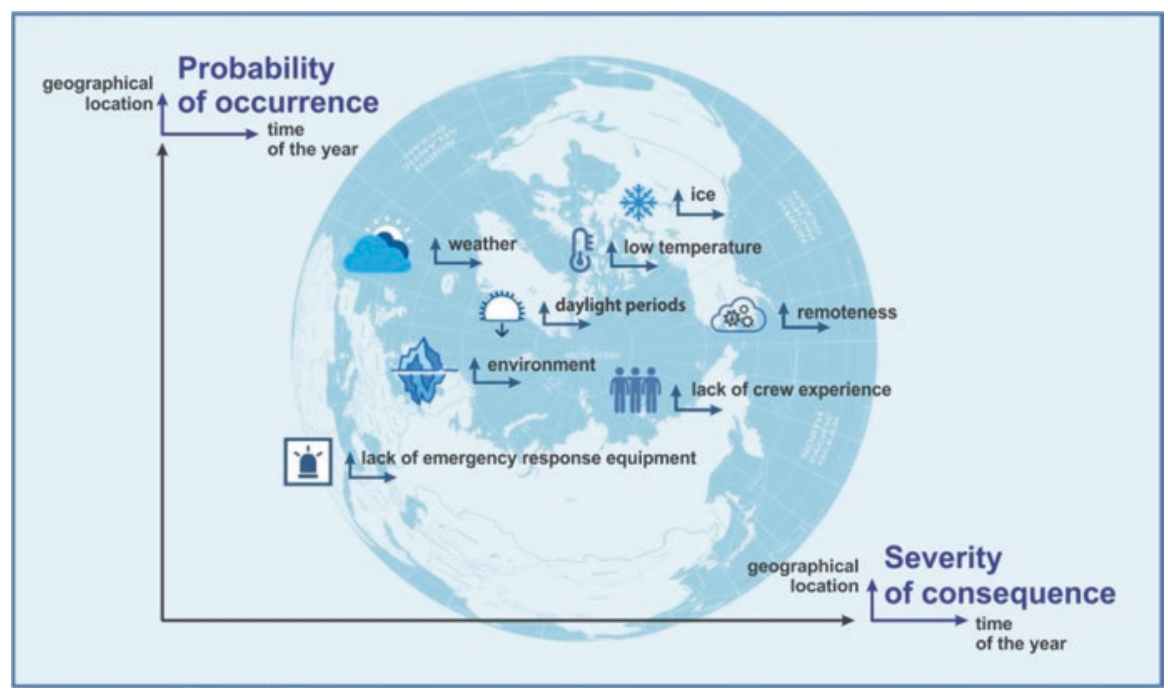

Fig. 12.1 Graphical representation of sources of hazards in the Arctic

Note: (1) The twin dimensions of geographical location and time of the year associated with each variable add to the complexity and multidimensional nature of the hazards. (2) The position of each hazard in the graph does not represent its probability of occurrence or severity of consequence 
repair facilities is rather limited. Remoteness implies lower capability for search and rescue, and lack of adequate resources implies limited capacity for post-incident response. Then there is emerging consideration of hazards to navigation due to inadequacies of navigational risk assessments and marine spatial planning (Schröder-Hinrichs et al. 2013; Mehdi et al. 2019).

Regardless of the adverse climate and severe challenges, the Arctic is known to have been traversed since olden time, although the earliest documented transit of the Northwest Passage (NWP) dates to 1906. While trans-Arctic voyages in the past were few and far between, declining ice cover in more recent times is leading to an increasing spiral of shipping traffic with attendant concerns for maritime safety and the fragile marine environment. Between 1980 and 2018, the minimum extent of Arctic ice declined sharply from 7.7 to 4.71 million square kilometres (NSIDC 2019). Of the eight nations bordering the Arctic (Canada, Denmark (Greenland), Finland, Iceland, Norway, Sweden, Russian Federation, and the United States), the Canadian Arctic, for example, encompasses more than 150,000 kilometres of coastline and provides habitat for a majority of the world's beluga and bowhead whales, narwhals, and polar bears and witnesses some of the greatest marine mammal and seabird migrations on the planet (The Pew Charitable Trusts 2016). Given the slow rate of recovery of the natural environment in those areas, any shipping accident could potentially have very serious consequences for the vulnerable Arctic ecosystems, alongside other safety implications.

When it comes to shipping incidents, the Arctic presents unique risks. An early example is the cruise liner Maxim Gorky who collided with an iceberg in June 1989, with nearly 1000 passengers, in the Greenland Sea north of Norway and listed heavily having sustained two gaping holes in her side. Grounding of ships at frequent intervals is of particular concern. The Hanseatic ran aground twice, breaching two of her fuel tanks in August 1996 and sustaining a 5-meter hole in her hull on the second occasion in 2005. The Clipper Adventurer grounded in 2010, and less than 2 years later, in 2012, the tanker Nanny, carrying 9.5 million litres of diesel, was the fifth to be grounded since 2007, threatening environmental disaster in an area that allows little margin for error. The more recent August 2018 grounding of the research vessel Akademik Ioffe in the Gulf of Boothia, Canada, passed without danger although it was a harrowing experience for the 102 passengers and 24 crew members on board (Struzik 2018).

It is, however, remarkable that the response efforts in each incident met with success. Passengers who abandoned the Maxim Gorky into lifeboats were rescued by the Norwegian Coast Guard vessel Senja that arrived on scene within 4 hours of the incident (Lohr 1989). One hundred fifty-three passengers aboard the Hanseatic were evacuated by helicopter. One hundred twenty-eight passengers from the Clipper Adventurer, along with 69 crew, were safely rescued (Struzik 2018). Concerns remain nevertheless, and, therefore, when the Crystal Serenity ferried the largest ever number, about 2000 passengers and crew, through the NWP on her maiden voyage in the Arctic in August 2016, several questions arose about the availability and capacity for response in the region, especially for mass rescue operations 
to the extent that it is described as a "wicked" cross-cutting policy problem that challenges many policy structures (Waldholz 2016; Pincus 2015).

Recognizing the fact that cooperation is an excellent way to overcome challenges, consequent to the Maxim Gorky incident, Finland actively engaged with the Arctic states regarding protection of the Arctic environment and organized the Rovaniemi meeting in September 1989 and followed up with three more meetings, which concluded in June 1991 with the adoption of a multilateral nonbinding agreement, the Arctic Environmental Protection Strategy (AEPS) (Arctic Council 1991). The AEPS was a first step to the 1996 Ottawa Declaration, which established the Arctic Council (Arctic Council 1996). This circumpolar forum currently promotes proactive cooperation, coordination and interaction among the Arctic states to address the risks of shipping and related issues of environmental protection in the Arctic. Two working groups of the Council are of particular interest - the Emergency Prevention, Preparedness and Response (EPPR) Working Group, which works for the protection of the Arctic environment from the threat or impact of an accidental release of pollutants as well as considering search and rescue-related issues, and the Protection of the Arctic Marine Environment (PAME) Working Group, which serves as the focal point for activities related to the protection and sustainable use of the Arctic marine environment (PAME 2018).

However, recurring incidents underscore the need for a well-rounded perspective on the risks associated with polar shipping and for innovative ways and means of addressing the identified risks. This chapter focuses on the goal-based regulatory framework of the International Maritime Organization (IMO) for enhancing maritime safety and prevention and control of marine pollution. Section 12.2 touches upon the key role of IMO in setting global standards and discusses the transition from the prescriptive to goal-based approach with reference to the Arctic. Section 12.3 discusses the implementation of the IMO goal-based standards (GBS) for Arctic shipping, with focus on the case of Canada. The chapter concludes with new insights and future pathways to a tiered implementation of the IMO GBS framework in Sect. 12.4.

\subsection{IMO Goal-Based Standards and the Arctic Context}

\subsubsection{IMO as a Global Regulatory Authority}

As regards global standards for ensuring safety and security of international shipping and the protection of the marine environment, it is IMO in its capacity as a specialized agency of the United Nations which serves as the global regulatory authority. IMO develops on a continual basis and maintains an effective framework of universally adopted and implemented regulations that cover every aspect of international shipping, from design, construction, equipment, manning, and operations to environmental protection and ship recycling. Indeed, when it comes to advancement of international maritime safety standards, IMO plays a key role having adopted over 50 international instruments and numerous codes, guidelines and circulars. 


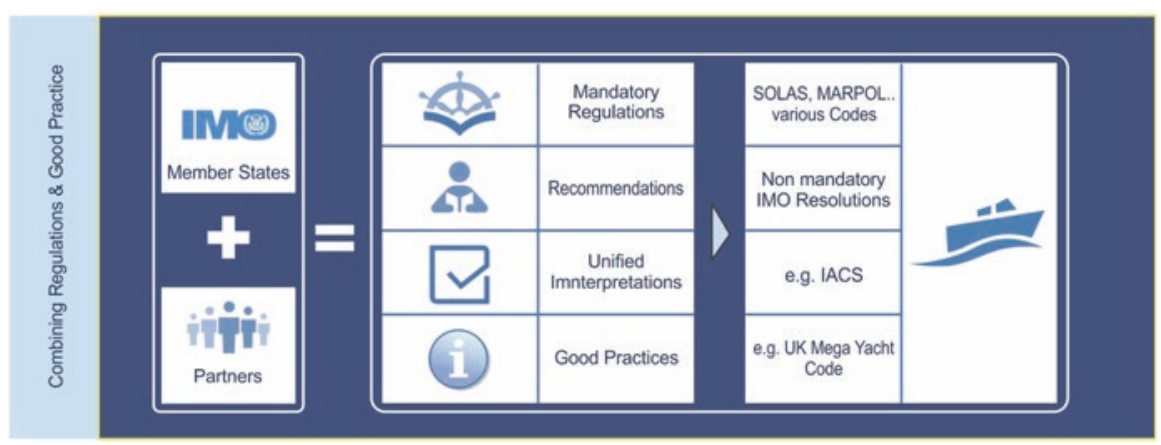

Fig. 12.2 IMO framework and process of shipping regulation (Schröder-Hinrichs 2018)

Figure 12.2 is a simplified depiction of the rather complex framework of the IMO system of regulations and its basis in compromises agreed to by the international maritime community.

\subsubsection{IMO's Transition to Goal-Based Standards}

Rules and regulations for international shipping adopted at IMO are organic in nature and require periodic refining based on research and experience and the level of risk deemed acceptable to the member states. Adoption of prescriptive rules and regulations was the classic approach to standard setting. The emerging focus at IMO on a goal-based regulatory framework marks a significant cultural shift from a culture of compliance, governed by a complex system of prescriptive statutory international and national regulations, classification rules, and industry standards to a culture of benchmarking, supported by functional risk-based requirements. According to IMO (2019a), GBS are goals and functional requirements that should be met through regulations, rules, and standards. The guiding principle is to establish clear, demonstrable, and verifiable goal-based standards such that the risk to the cargo, crew, and the environment from a properly built, operated and maintained ship is as low as reasonably practicable during its specified design life. The International Code for Ships Operating in Polar Waters (Polar Code 2014/2015), which is elaborated on below, the International Code of Safety for Ships Using Gases or Other Low-flashpoint Fuels (IGF Code) (IMO 2015a), and the goal-based ship construction standards for bulk carriers and oil tankers (IMO 2009a) are examples of IMO instruments based on the GBS approach. It is intended that overarching goals and their related functional requirements will allow for novel designs that meet the required level of safety which, when applying prescriptive regulations, would have to be treated under the existing provisions for alternative design arrangements (see SOLAS regs II-1/55, II-2/17, and III/38) which may not achieve a globally harmonized implementation as such alternative arrangements are subject to 
individual flag state interpretations. A goal-based approach, however, provides not only a global standard but also promotes new technology and greater innovation within the shipping industry.

The transition to risk-based considerations and the change in the basis for rulemaking at IMO are in keeping with demands for objective evidence of the need to develop new regulations or to amend existing ones. The formal safety assessment procedure (IMO 2018) for the evaluation of risks signifies the transition, and SchröderHinrichs (2018) cites the elements of risk-based considerations that are to be found in several IMO instruments. For example, under the International Convention for the Safety of Life at Sea (SOLAS 1974), the position of aids to navigation is to be determined on the basis of risk assessments, while alternative designs and arrangements such as for oil tankers or fire safety are required to demonstrate that the suggested design deviations from prescriptive regulations meet the required safety levels (IMO 2001, 2003, 2006a). Similarly, both designation and decisions on requests for places of refuge involve two independent risk assessments. Another example is the designation of Particularly Sensitive Sea Areas for which a cause relationship must be demonstrated when suggesting associated protection measures. After having implemented risk-based approaches, a further transition to goal-based standards with its safety level approach in five hierarchical tiers was the logical next step. ${ }^{1}$

As per the IMO (2019a) goal-based standards framework in Fig. 12.3, risk assessment is integral to the development of a GBS, which may be for new regulations or based on existing prescriptive ones. When developing GBS, the goals or high-level objectives to be achieved are defined at the very outset. A hazard identification (HAZID) process, possibly guided by the IMO Formal Safety Assessment Guidelines (IMO 2018), is the first step and the basis for a risk analysis and the formulation of risk mitigating functions. The HAZID itself may be system- or process-based and conducted in varying degrees of detail leading to varying degrees of detail of the functions developed consequentially. Functions are supplemented by the expected performances that specify the effectiveness to be achieved. These performance requirements provide the criteria for verifying compliance with the goal and form part of the functional requirements (IMO 2019b).

\subsubsection{Risk-Based Approaches and Maritime Safety in the Arctic}

In terms of risks for operations in the Arctic, the harsh marine environment presents unique and significant challenges to a vessel and its crew. The risks of frostbite and hypothermia are drastically accelerated in sub-zero temperatures (Transport Canada

\footnotetext{
${ }^{1}$ The UK Health and Safety Regulation is believed to be one of the longest running applications of a goal-based approach to regulations and traces its origins to the 1972 Robens Report (UK HSE 1972).
} 


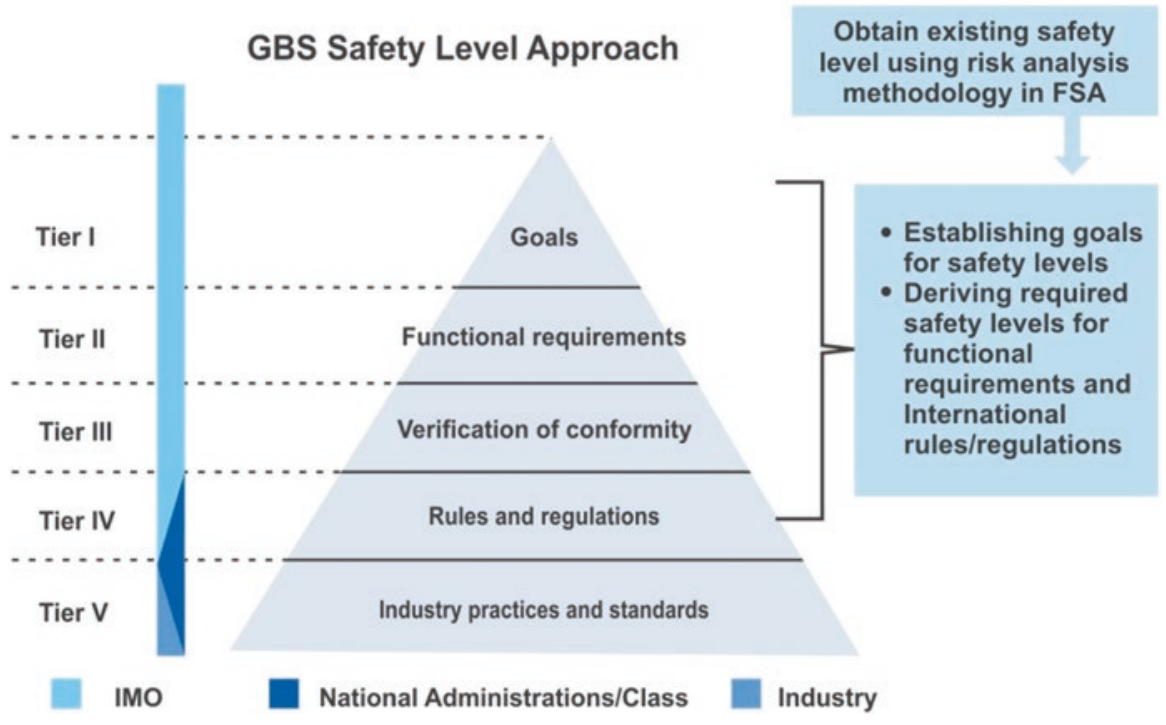

Fig. 12.3 IMO safety case goal-based standards framework (IMO 2019a)

2011). Extreme cold and the use of heavy gloves affect tactile sensitivity and manual dexterity (Parsons 2014; Islam et al. 2017). Compared to navigation in calm water conditions, ice passage can increase whole-body vibration exposure by a factor of 11 (Bekker et al. 2017). Icicles overhead can break off and fall on seafarers, and snow and ice underfoot can cause them to slip and fall. All these, together with accidental immersion, excessive ultraviolet light, extreme contrasts in the length of day or night, and unusual weather conditions that affect both visibility and the sea state, influence performance and decision-making in seafarers. The conditions associated with navigation in the polar regions present physical and cognitive risks to seafarers that can affect not only their personal safety but also their ability to control the vessel and its systems (Sillitoe et al. 2010).

Materials used for the hull structure and equipment may not be suitable in terms of class or design service temperature in polar regions. Contents of tanks for fresh water, ballast, and fuel oil will be susceptible to freezing. Vent pipes, valves, and suction lines may suffer blockages. The bow will be particularly vulnerable to sea spray and ice accretion. Vessel stability could be impaired by ice build-up on the hull. Cold air could have unintended effects on systems and machinery. Engines may not fire because of low combustion air temperature. The ship's anchoring system and navigational systems such as the radar would suffer from icing. Some navigation and communication systems do not work in high latitudes. Safety systems such as life-saving appliances and firefighting and protection systems may fail to perform due to freezing. The presence of ice on the sea surface may even inhibit deployment of life boats. Some ship types, such as tankers, bulk carriers, and liquefied natural gas (LNG) carriers, may require further special consideration of 
design and operational features. Indeed, in Arctic conditions, many systems and components could be operating at or near their design limits (ABS n.d.).

The management of risks for ships plying the Arctic begins with the owner defining the operational limitations for the ship by selecting the ice class, design temperature or rather the polar service temperature (PST), working latitude of the navigation and communication equipment, and the expected time to rescue based on the operating area (Hindley 2017). The IMO Polar Code includes risk management as part of ice class selection (Operational Assessment), by way of requirements for voyage planning, as part of tactical ice navigation (Polar Operational Limit Assessment Risk Indexing System (IMO 2016a)), operational limitations as reflected in the Polar Ship Certificate, and the Polar Water Operational Manual guiding operational decision-making on board.

From a design perspective, in the context of the Arctic, a failure mode and effects analysis (FMEA) on machinery and systems or any other suitable risk-based technique is imperative early on in the design stage. ${ }^{2}$ Risk assessment is indeed de rigueur to the evaluation of new conceptual designs, particularly for Arctic operations. The goal is to identify hazards and failure modes applicable to a novel concept application vis-à-vis the control of these hazards and failure modes so as to verify the novel aspects not covered by any of the existing rules, codes, and standards. A qualitative risk assessment comprising HAZID (hazard identification), What-if, or HAZOP (hazard and operability study) is generally the first step. It will usually involve a brainstorming session with structured discussions on the proposed concept together with a consideration of the risk ranking methodology or risk matrix. The qualitative assessment will be followed up with a more detailed quantitative risk assessment such as fault trees and event trees to verify that the identified risks are properly managed.

Several projects underway are devoted to the concept of risk-based design. An integrated risk-based design framework is being developed as part of the SEDNA research project of the European Union's Horizon 2020 program. The project includes an analysis of the key parameters affecting the risk level of ships in ice together with the possible risk control options that will allow ships designed for the Arctic to be measured against the actual risks that they will experience in operation (SEDNA n.d.). Classification societies are partnering with the industry to develop holistic, risk-based design and the concept of mission-based design is being explored to address the challenges of navigating in the Arctic (ISSC 2015). Apart from riskbased design, scholars are also investigating accident models specific to the Arctic, such as the collision risk factors analysis model for icebreaker assistance in icecovered waters (Zhang et al. 2018).

There are advantages of risk- and goal-based approaches in the context of the Arctic. However, risk-based design for the Arctic is challenging as the ice environment, together with all the possible ship-ice contact scenarios, is complicated

\footnotetext{
${ }^{2}$ FMEA is a useful tool to not only identify design changes to equipment or systems or possibly provide additional features, but also to prevent failures from occurring or to mitigate consequences if a failure were to occur.
} 
and difficult to define properly, especially in proper probabilistic terms. The main challenge is still how to describe the ship-ice interaction parameters such as ship-ice contact characteristics, pressure distributions, and load levels in all the various ice conditions. The possible environmental consequences of accidents also need further research, and human factors need to be incorporated in risk analysis techniques (Kujala et al. 2019).

Theoretical analyses identify many contextual factors that could impact the effectiveness of GBS and regulations. The GBS approach depends on interpretative practices and whether or not it is possible to develop a shared understanding of the goals and concepts; therefore, their effectiveness could be impaired by any deficit of trust between the regulator and the regulated. A major practical challenge is to monitor and assess achievement of goals and identify the desired levels of performance or, rather, the precise point at which a goal may be deemed to have been satisfied (Decker 2018). As regards the risk-based approaches in maritime safety, some of the impending challenges are varying levels of risk acceptance, varied approaches, requirement of new resources, and new competences within maritime administrations to evaluate and approve riskbased designs and possible alienation of some stakeholders (Schröder-Hinrichs 2018).

\subsubsection{IMO Instruments for Arctic Shipping}

Owing to the unique nature of risks in the Arctic, the IMO is paying particular attention to these polar waters, also including the Antarctic area. Among the first attempts at the IMO to provide common baselines of requirements for polar shipping was an Arctic-focused document by Germany in the early 1990s. In keeping with the two-pronged approach adopted by consensus thereafter, the IMO developed broad Guidelines for Ships Operating in Arctic Ice-covered Waters in 2002 (IMO 2002b, 2009b) that were recommendatory in nature, while the International Association of Classification Societies (IACS) developed detailed Polar Class Unified Requirements (IACS 2016), which in turn were accepted by IMO. In 2007, taking note of the growing popularity of the Arctic and the Antarctic as an exotic destination for cruise ships, IMO (2007, 2006b) adopted Guidelines on Voyage Planning for Passenger Ships Operating in Remote Areas as additional non-mandatory standards for the operation of passenger ships (Deggim 2010). However, diverse national and regional regulations governing polar shipping continued to prevail in the absence of a clear and mandatory international standard applicable to ships of all member states, leading eventually to the adoption of the mandatory Polar Code (IMO 2014/2015b) ${ }^{3}$ supplementing requirements mandatory

\footnotetext{
${ }^{3}$ The Polar Code consists of two parts: Part I Safety Measures, of which Part I-A covers mandatory measures in 12 chapters and Part I-B recommendatory Additional Guidance to Part I-A, and Part II Pollution Prevention Measures (Environmental Protection Measures), of which Part II-A covers mandatory measures in five chapters and Part II-B recommendatory Additional Guidance.
} 


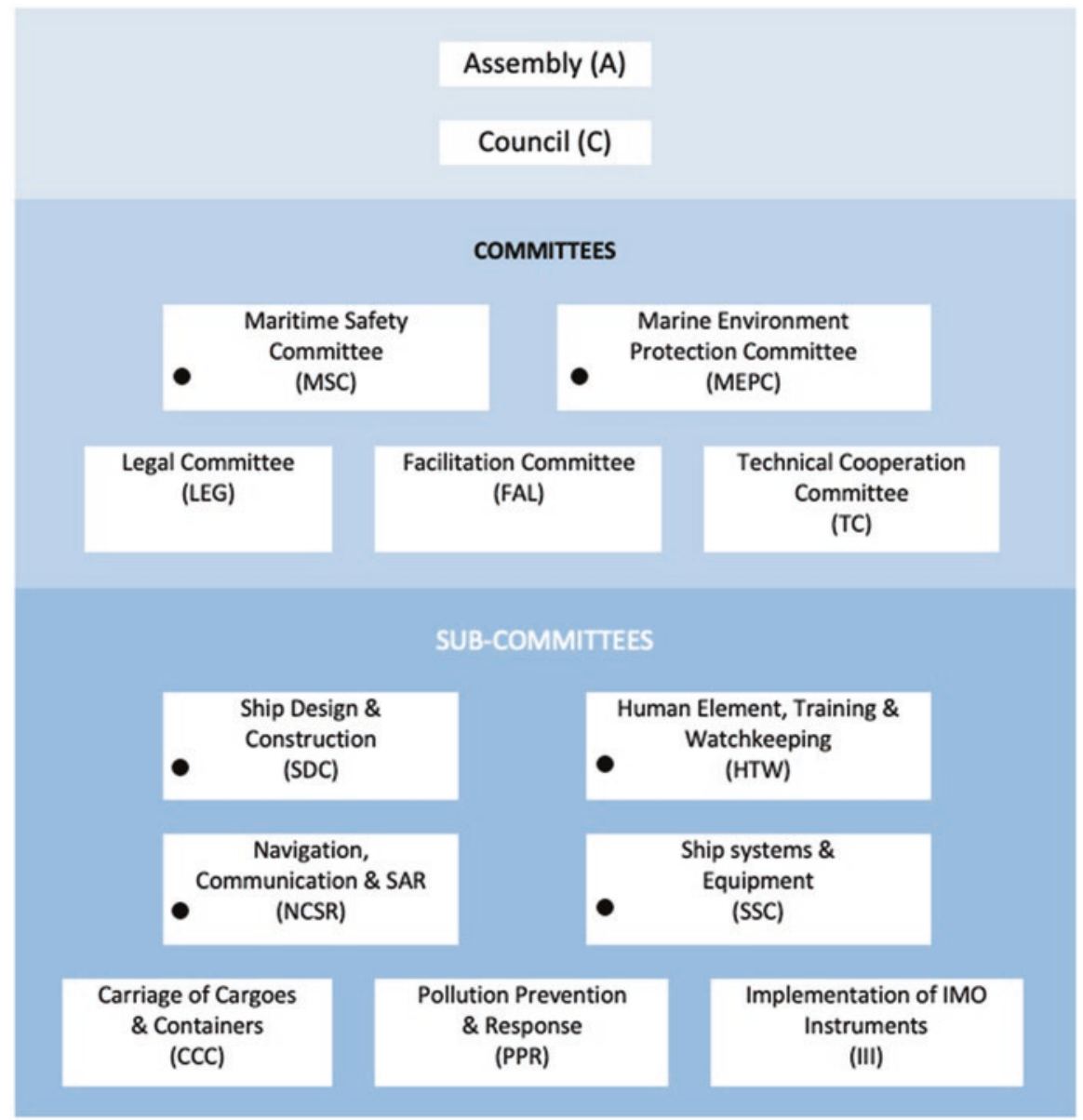

Fig. 12.4 IMO organizational structure and work on the Polar Code (enotes Committees or Sub-Committees with Polar Code work items)

under IMO instruments such as SOLAS, the International Convention for the Prevention of Pollution from Ships (MARPOL 1973/78), and the International Convention on Standards of Training, Certification and Watchkeeping for Seafarers (STCW) for ships operating in the polar regions. Figure 12.4 depicts the extensive work across the committees and sub-committees at IMO which resulted in the adoption of the Code.

The IMO Polar Code consists of mandatory safety and pollution prevention (environmental protection) measures as well as recommendatory additional guidance for each set of measures. The Polar Code is risk-based, containing functional requirements and prescriptive provisions. The key principles for developing the Polar Code were the use of a risk-based approach in determining the scope and the adoption of a holistic approach in reducing identified risks. The goal of the Code is to provide for safe ship operations and the protection of the polar environment by 
addressing risks present in polar waters and not adequately mitigated by other IMO instruments. The Code not only regulates navigation in Arctic and Antarctic waters in legal terms, but also aims at mitigating risks in the polar areas through the identification of hazard sources and institutionalization of procedures for risk assessment (Deggim 2018).

The safety measures mandated by the Polar Code cover structure, sub-division and stability aspects of design and construction as well as specifications for machinery, fire safety, life-saving appliances and communications. A Polar Water Operational Manual, required to be carried on board, provides information regarding the ship's operational capabilities and limitations in order to support the decision-making process. A Polar Ship Certificate is required by the Code stating, inter alia, the ice class of the ship, which defines the limitations for operations in ice. Additional training and certification requirements for masters and deck officers on ships operating in polar waters have been made mandatory through amendments to the STCW Convention and Code, 2010 (IMO 2016b, c).

While the Polar Code encourages ships not to use or carry heavy fuel oil (HFO) in the Arctic, a regulation providing for a ban on HFO is under discussion at IMO in the Marine Environment Protection Committee (MEPC) and its Sub-Committee on Pollution Prevention and Response (PPR) with the aim of protecting the fragile polar environment from increasing shipping emissions. The ban would eventually be inevitable, given the fact that the traffic of cruise ships fuelled by HFO has increased nearly 35\% between 2005 and 2017 and HFO combustion produces high levels of black carbon emissions which, among other impacts, accelerate melting when deposited on Arctic snow and ice, aggravating the climate crisis. ${ }^{4}$

Nevertheless, there is scope for improvement and several areas within the IMO regulatory framework for the Polar waters may merit further work. For example, extremely low temperatures could adversely affect certain dangerous goods while being transported through the Arctic. In this context, the International Maritime Dangerous Goods Code (IMO 2002a) and the International Code for the Construction and Equipment of Ships Carrying Liquefied Gases in Bulk Code (IMO 2014b), both mandatory under Chapter VII of SOLAS, would require a review to address this aspect (Arctic Council 2009, 55-56). Meanwhile, recognizing that over a third of the shipping in the Arctic comprises non-SOLAS vessels, a discussion is underway at IMO's Maritime Safety Committee (MSC) on follow-up work to the adoption of the Polar Code, identifying safety measures that would be applicable to vessels outside the remit of the SOLAS Convention, such as fishing vessels, small cargo ships and pleasure yachts. Similarly, the mandatory ship reporting system currently applicable to the Barents Area (IMO 2012) could be extended to the NWP, although the need is currently fulfilled by Canada's national legislation which mandates ship reporting (see below).

\footnotetext{
${ }^{4}$ Three related points of interest: a HFO ban is already implemented in the Antarctic; a global limit of the sulphur content of fuel oil enters into force on 1 January 2020; and a probably bigger environmental issue is the risk of HFO spills in polar waters (IMO 2015c).
} 


\subsection{Implementation of IMO Safety Case Goal-Based Standards Framework in the Arctic}

\subsubsection{The Role of Classification Societies in Implementation}

Traditionally, in the prescriptive framework, it would suffice for the national maritime administration to develop a clarification of the intent and application of the IMO convention regulations and IMO resolutions, particularly on those matters in the convention which are left to the satisfaction of the flag administration or where more precise wording is found to be necessary. Such clarifications are found as either regulations issued by an administration or Unified Interpretations applied by IACS member societies to ships whose flag administration has not issued instructions on the interpretation of the regulations concerned (IACS 2011).

In contrast to the rigorous prescriptive framework, the IMO GBS establish broad, overarching safety, environmental, and/or security standards which are "clear, demonstrable, verifiable, long standing, implementable and achievable, irrespective of ship design and technology and specific enough in order not to be open to differing interpretations" (IMO 2011). It is thereafter the responsibility of the national administration of each IMO member state to develop national complementary regulations that may be required to meet the goals, functional requirements, and associated regulations of an IMO instrument. An administration may task a Recognized Organization (RO), often class societies, to develop detailed requirements that will allow industry to meet the safety objective. Thus, for example, IMO (2010) adopted goal-based ship construction standards for bulk carriers and oil tankers (the Standards) requiring these ship types to be designed, built, and maintained in accordance with the Standards which are, for the time being, solely met by class societies' individual rule sets and their Common Structural Rules (CSR). The CSR form the core of the rule set required to meet the functional requirements of the Standards.

In respect of the traditional role played by classification societies, the stipulation in 1881 by Det Norske Veritas (DNV) requiring sufficient additional strengthening in the extreme forepart of the vessel by closer frame spacing than directed in the rules or the adoption of some alternative means is the earliest known classification society rule for vessels having to steam through ice (Snider and Jamieson 2015, 2). Thereafter, the first special requirements for ships intended for operation in icecovered waters were introduced in 1932, also by DNV. These rules required increased scantlings of frames, plates, and stringers given as a percentage increase (15-25\%) above normal class rules. The Finnish-Swedish Ice Class Regulations, which have been elaborated and issued since 1971, were instrumental for the Polar Code. In 2006, IACS developed detailed Polar Class Unified Requirements (UR) as amplification of the then prevailing IMO Guidelines for Ships Operating in Arctic Ice-covered Waters. The descriptions and application (UR I1), structural requirements (UR I2), and machinery requirements (UR I3) which comprise the Polar 
Class UR have since undergone several rounds of revisions. ${ }^{5}$ The IACS Polar Class set out seven classes of construction (lowest class 7, to highest class 1) based on whether the vessel is intended to operate seasonally or year-round and the ice conditions in which the vessel is expected to operate in as defined by WMO (World Meteorological Organization) Sea Ice Nomenclature.

The winterization requirements of the classification societies for hull construction, machinery equipment, and operational parts also supplement the IMO's goal-based standards for the Arctic. The Russian Maritime Register of Shipping (RS) requirements for ship equipment serve to ensure long-term operation at low temperatures. DNV Ice Class Rules Sections 6 and 7 relate to winterization and design ambient temperature (DAT) requirements.

\subsubsection{Implementation by Member States: The Case of Canada}

Whereas flag states have traditionally had the responsibility to transpose instruments adopted at the IMO into their national legislation, when it comes to implementation of IMO regulations, such as the Polar Code, administrators will require a different level of knowledge and skill sets including good knowledge of the various design elements. From a coastal state viewpoint, Article 234 of the United Nations Convention the Law of the Sea (UNCLOS 1982) grants Arctic state parties the right to adopt and enforce nondiscriminatory laws and regulations for the prevention, reduction, and control of marine pollution from vessels in ice-covered areas within the limits of the exclusive economic zone (EEZ) (Chircop 2012). From either perspective, Canada makes for an excellent case study for member state implementation given its significant influence in Arctic waters and jurisdiction over large swathes of the NWP (see also Chap. 15 in this volume).

Canada implemented comprehensive special ship construction, equipment, and crewing requirements together with stringent pollution prevention standards through the Arctic Waters Pollution Prevention Act (AWPPA) in 1970, long before their introduction in MARPOL (AWPPA 1970; AWPPR 1978). The legislation, which is regarded as a pioneer at addressing the hazards facing Arctic shipping (Struzik 2018; Jensen 2007), originally applied to a 100-nautical-mile pollution prevention area, but recent amendments extend the application to the 200-nautical-mile EEZ (Arctic Council 2009, 66-67). Additionally, Shipping Safety Control Zones adopted under the AWPPA stipulate the areas and time period for operation of ships based on their ice classification. Vessel traffic services zones implemented as a voluntary vessel reporting and clearance system in the Arctic shipping safety control zone are a mandatory requirement with effect 1 July 2010 for ships entering the Canadian Arctic waters north of $60^{\circ} \mathrm{N}$ under the Canada Shipping Act, 2001 (CSA 2001;

\footnotetext{
${ }^{5}$ Prevailing UR are as follows: UR I1, Rev.2 Apr 2016; UR I2, Rev.3 Apr 2016; and UR I3, Rev.1 Corr.1 Oct 2007.
} 
NORDREG 2010; Arctic Council 2009, 66-67). Canada also led the Working Group established by the IMO Sub-Committee on Ship Design and Equipment (now the Sub-Committee on Ship Systems and Equipment (SSE)), the work of which culminated in the adoption of the Polar Code.

The Polar Code, Sect. 12.3, stipulates a requirement of advanced training for the master and chief mate and basic training for officers in charge of a navigational watch in other than open and ice-free waters. Canada developed the IMO model courses on basic and advanced training for ships operating in polar waters. Canada's national legislation (the Arctic Shipping Safety and Pollution Prevention Regulations (ASSPPR), s 10) requires vessels other than a cargo vessel of 500 gross tonnage or more, or a passenger vessel certified under SOLAS, to have an ice navigator on board if the master or person in charge of deck watch does not hold a certificate in advanced training for ships operating in polar waters in accordance with Regulation V/4 of the STCW Convention. A person qualifies to be recognized as an ice navigator if he or she has served in the capacity of master or person in charge of the deck watch for at least 50 days, with a minimum 30 days in Arctic waters, in ice conditions (ASSPPR 2017).

The good work being done by Canada is not without critique though. The Pew Charitable Trusts report (2016) notes that Canada, owing to a lack of a cohesive vision for Arctic shipping policy and insufficient funds, has been unable to implement recommendations for policy improvement, including recommendations for reforms by several key government studies. Based on its research and taking a cue from the Canadian Coast Guard Northern Marine Transport Corridors Initiative, the Trusts proposed an Integrated Arctic Corridors Framework, a system of shipping corridors according to assessed risk that would implement targeted routeing and site-specific management strategies.

It may also be argued that while Canada is among the eight nations that border the Arctic, all states involved in Arctic shipping share responsibility for navigational safety and environmental protection as per Article 194 of UNCLOS. Moreover, while national regulation is best suited to serve as a complement, especially towards elaboration of goal-based regulation, it has its fair share of limitations, and, consequently, regional cooperation initiatives in the Arctic are desirable and also recommended by the IMO. In this context, the Arctic Council's 2011 Arctic Search and Rescue Agreement and 2013 Agreement on Cooperation on Marine Oil Pollution Preparedness, Response and Cooperation in the Arctic serve as excellent examples of cooperation in the Arctic.

\subsection{Future Pathways in Risk-Based Approaches and Goal-Based Standards for the Arctic}

As regards future pathways, like any another instrument developed at the IMO, the Polar Code will need further work in view of the experience gained with its implementation (Jensen 2007). For example, icing of lifeboats and launching equipment 
impinges on safety of life at sea. There is scope for elaborating measures to prevent, mitigate, and avoid sea spray icing of vessels. Further, reference could be made to factors such as wind speed, air temperature, and ship speed that determine the potential for such icing. Provision could also be made for alternative ice removal equipment. Measures could also be specified for protection of vital components on deck. In fact, several areas for further development of the Polar Code have been identified in the literature. These include risk assessment of operational capabilities and limitations in ice, additional performance and test standards for the equipment and systems on board ships, ship routeing measures and reporting systems, polarspecific rules on the use of antifouling paints and ballast water management, and a ban on the use and carriage of heavy fuel oil in Arctic waters (Sun 2018).

It is recognized that strengthening regulations is a continuing process at IMO. Even as this chapter is penned, the MSC approved two guidance circulars at its 101st session addressing communication equipment de-icing/ice accretion (IMO 2019c) and life-saving appliances and arrangements for ships operating in polar waters (IMO 2019d). Further, relevant sub-committees at the IMO (see Fig. 12.4) continue working on the output "Consequential work related to the new International Code for Ships Operating in Polar Waters". The SSE Sub-Committee is also reviewing the International Life-Saving Appliance Code and the relevant IMO resolutions to adapt current testing and performance standards to the Polar Code provisions or develop additional requirements, develop guidance on extinguishing media at polar service temperatures, and also consider any necessary amendments to current standards for firefighters' outfits.

Given the fact that the regulations adopted at the IMO represent the minimum common standard for shipping agreed upon by the collective member states, such "one-size-fits-all" prescriptive regulations may not be adequate to meet all the considerations of safety, security, and environmental protection of international shipping in particularly harsh climates such as the Arctic. A supplement to the principal safety legislation such as the Polar Code may specify enhanced requirements for ships, but even this GBS approach purports to partly meet safety requirements for ships operating in the polar regions while expecting member states to fill in at lower tiers of the GBS framework. In this context, the risk-based approach bears immense potential and utility in development of the future regulatory framework at the IMO. While regulations would be justified by risk analysis based on agreed risk acceptance criteria, the regulations themselves could be simple requirements that do not refer to risk and may even be prescriptive. Nonetheless such a risk-based framework would be open for risk-based design and thereby suited for implementation in all climes and jurisdictions with due diligence by flag administrations.

In conclusion, it may be said that the IMO safety case goal-based standards framework provides an advantageous synergy of "risk-based" efforts at all levels for enhancing safety of ships. While the IMO continues to establish and maintain a complex global legal regime for safety of ships and environment protection, including standards for navigation and protection of the marine environment, the inadequacies, if any, in the IMO's global legal regime present an opportunity for the coastal states to supplement or fill in with their own set of regulations. In the context 
of the Arctic, the array of unmitigated hazards provides coastal states such as Canada with ample opportunities to play an important role in undertaking mitigation measures such as enhancing navigation aids, collecting bathymetric information and updating charts, augmenting vessel traffic services, diversifying ship repair facilities, designating places of refuge, strengthening the capacity for search and rescue and pollution response, and extending the applicability of regulations in equal measure to non-conventional vessels and fishing vessels. Of course, as the expenditure exceeding CDN\$500,000 consequent to the grounding of the Akademik Ioffe highlights, there is always the question as to what extent should a coastal state invest towards fulfilment of its obligations. Lastly, while the Polar Code and other instruments may be regarded as among the first steps, initiatives such as joining the Arctic Council as an official observer in May 2019 are testimony to IMO's continuing endeavours at working closely with Arctic states, regional organizations, and the international maritime community to build an effective and efficient regime to reduce the risks associated with Arctic shipping.

\section{References}

ABS (American Bureau of Shipping). (n.d.). Low temperature operations: Guidance for Arctic shipping. Houston: ABS.

Arctic Council. (1991). Arctic environmental protection strategy, Rovaniemi, Finland, 14 June.

Arctic Council. (1996). Declaration on the establishment of the Arctic Council, Ottawa, Canada, 19 September.

Arctic Council. (2009). Arctic marine shipping assessment 2009 report. Tromsø: Arctic Council.

Arctic Council. (2011). Agreement on Cooperation on Aeronautical and Maritime Search and Rescue in the Arctic (12 May 2011, entered into force in 2013).

Arctic Council. (2013). Agreement on Cooperation on Marine Oil Pollution Preparedness, Response and Cooperation in the Arctic (15 May 2013, entered into force in 2016).

ASSPPR. (2017). Arctic Shipping Safety and Pollution Prevention Regulations, SOR/2017-286 (Canada).

AWPPA. (1970). Arctic Waters Pollution Prevention Act, RSC 1985, c A-12 (Canada).

AWPPR. (1978). Arctic Waters Pollution Prevention Regulations, CRC, c 354 (Canada).

Bekker, A., Soal, K. I., \& McMahon, K. J. (2017). Whole-body vibration exposure on board a polar supply and research vessel in open water and in ice. Cold Regions Science and Technology, $141,88-200$.

Chircop, A. (2012). Regulatory challenges for international Arctic navigation and shipping in an evolving governance environment. Presented at the annual meeting of the Comité Maritime International, Beijing, China, 14-19 October.

CSA. (2001). Canada Shipping Act, 2001, SC 2001, c 26.

Decker, C. (2018). Goals-based and rules-based approaches to regulation (BEIS Research Paper No. 8). London: Department for Business, Energy and Industrial Strategy. http://www.econis. eu/PPNSET?PPN=1067716548. Accessed 4 July 2019.

Deggim, H. (2010). Ensuring safe, secure and reliable shipping in the Arctic Ocean. Presented at NATO Advanced Research Workshop on Environmental Security in the Arctic Ocean, Scott Polar Research Institute, Cambridge, UK, 13-15 October.

Deggim, H. (2018). The International Code for Ships Operating in Polar Waters (Polar Code). In L. Hildebrand, L. Brigham, \& T. Johansson (Eds.), Sustainable shipping in a changing Arctic (WMU Studies in Maritime Affairs) (Vol. 7, pp. 15-35). Cham: Springer. 
Hindley, R. (2017). Risk management in ice covered waters. Presented at SPICES Workshop, Sea Ice Extremes and Operations in the Polar Oceans, Helsinki, Finland, 1 March.

IACS (International Association of Classification Societies). (2011). Classification societies what, why and how? (Updated January 2015). http://www.iacs.org.uk/media/3785/iacs-classwhat-why-how.pdf. Accessed 4 July 2019.

IACS. (2016). Requirements concerning Polar Class, as amended 2 April 2016. http://www.iacs. org.uk/download/1803. Accessed 4 July 2019.

IMO (International Maritime Organization). (2001). Guidelines on alternative design and arrangements for fire safety, IMO Doc. MSC/Circ.1002 (26 June) (as amended by IMO Doc. MSC.1/Circular.1552, 25 November 2016).

IMO. (2002a). International Maritime Dangerous Goods Code, IMO Resolution MSC.122(75) (24 May).

IMO. (2002b). Guidelines for ships operating in Arctic ice-covered waters, IMO Doc. MSC/ Circ.1056 and MEPC/Circ.399 (23 December).

IMO. (2003). Revised interim guidelines for approval of alternative methods of design and construction of oil tankers, IMO Resolution MEPC.110(49) (18 July).

IMO. (2006a). Guidelines on alternative design and arrangements for SOLAS Chapters II-1 and III, IMO Doc. MSC.1/Circ.1212 (15 December).

IMO. (2006b). Enhanced contingency planning guidance for passenger ships operating in areas remote from SAR facilities, IMO Doc. MSC.1/Circ.1184 (31 May).

IMO. (2007). Guidelines on voyage planning for passenger ships operating in remote areas, IMO Resolution A.999(25) (29 November).

IMO. (2009a). Goal-based new ship construction standards: Guidelines on approval of risk-based ship design, submitted by Denmark, IMO Doc. MSC 86/5/3 (9 February).

IMO. (2009b). Guidelines for ships operating in polar waters, IMO Resolution A.1024(26) (2 December).

IMO. (2010). International goal-based ship construction standards for bulk carriers and oil tankers, IMO Resolution MSC.287(87) (20 May).

IMO. (2011). Generic guidelines for developing IMO goal-based standards, IMO Doc MSC.1/ Circ.1394 (14 June).

IMO. (2012). Adoption of a new mandatory ship reporting system "in the Barents Area (Barents SRS)", IMO Resolution MSC.348(91) (28 November).

IMO. (2014b). Amendments to the International Code for the Construction and Equipment of Ships Carrying Liquefied Gases in Bulk Code (IGC Code), IMO Resolution MSC.370(93) (22 May).

IMO. (2015a). International Code of Safety for Ship Using Gases or Other Low-flashpoint Fuels (IGF Code), IMO Resolution MSC.391(95) (11 June).

IMO. (2015b). Report of the Marine Environment Protection Committee on its Sixty-eighth session, IMO Doc. MEPC 68/21/Add.1 (5 June), Annex 10: IMO Resolution MEPC.264(68), International Code for Ships Operating in Polar Waters.

IMO. (2015c). Guide on oil spill response in ice and snow conditions, IMO Doc. PPR 3/15 (11 November).

IMO. (2016a). Guidance on methodologies for assessing operational capabilities and limitations in ice, IMO Doc. MSC.1/Circ.1519 (6 June), Appendix: Polar Operational Limit Assessment Risk Indexing System (POLARIS).

IMO. (2016b). Amendments to the International Convention on Standards of Training, Certification and Watchkeeping For Seafarers (STCW), 1978, IMO Resolution MSC.416(97) (25 November).

IMO. (2016c). Amendments to Part A of the Seafarers' Training, Certification and Watchkeeping (STCW) Code, IMO Resolution MSC.417(97) (25 November).

IMO. (2018). Revised guidelines for formal safety assessment (FSA) for use in the IMO rulemaking process, IMO Doc. MSC-MEPC.2/Circ.12/Rev.2 (9 April). 
IMO. (2019a). Interim guidelines for development and application of IMO goal-based standards safety level approach, IMO Doc. MSC.1/Circ.1596 (15 February).

IMO. (2019b). Goal-based new ship construction standards: Proposal for amendments to the Generic guidelines for developing IMO goal-based standards (Generic Guidelines) (MSC.1/ Circ.1394/Rev.1), submitted by Germany, Netherlands and Sweden, IMO Doc. MSC 101/6/3 (6 March).

IMO. (2019c). Guidance for navigation and communication equipment intended for use on ships operating in polar waters, IMO Doc. MSC.1/Circ.1612 (14 June).

IMO. (2019d). Interim guidelines on life-saving appliances and arrangements for ships operating in polar waters, IMO Doc. MSC.1/Circ.1614 (26 June).

Islam, R., Abbassi, R., Garaniya, V., \& Khan, F. (2017). Development of a human reliability assessment technique for the maintenance procedures of marine and offshore operations. Journal of Loss Prevention in the Process Industries, 50(B), 416-428.

ISSC (International Ship and Offshore Structures Congress). (2015). Committee V.6. Arctic Technology (Vol. 2, pp. 769-816). 19th international Ship and Offshore Structures Congress, Cascais, Portugal, 7-10 September 2015.

Jensen, Ø. (2007). The IMO guidelines for ships operating in Arctic ice-covered waters: From voluntary to mandatory tool for navigation safety and environmental protection? (FNI Report 2/2007). Lysaker: Fridtjof Nansen Institute.

Kujala, P., Goerlandt, F., Way, B., Smith, D., Yang, M., Khan, F., \& Veitch, B. (2019). Review of risk-based design for ice-class ships. Marine Structures, 63, 181-195.

Lohr, S. (1989). All safe in Soviet ship drama. The New York Times, 21 June. https://www.nytimes. com/1989/06/21/world/all-safe-in-soviet-ship-drama.html. Accessed 4 July 2019.

MARPOL. (1973/78). International Convention for the Prevention of Pollution from Ships (2 November 1973), 1340 UNTS 184, as amended by the Protocol of 1978 Relating to the International Convention for the Prevention of Pollution from Ships (17 February 1978, entered into force 2 October 1983), 1340 UNTS 61.

Mehdi, R. A., Schröder-Hinrichs, J.-U., \& Baldauf, M. (2019). A tale of two industries: Seafarer perceptions of navigational safety risks near offshore wind farms. Ocean Yearbook, 33, 543-581.

NORDREG. (2010). Northern Canada Vessel Traffic Services Zone Regulations, SOR/2010-127.

NSIDC (National Snow \& Ice Data Center). (2019). Arctic sea ice news \& analysis. NSIDC, University of Colorado. https://nsidc.org/arcticseaicenews/. Accessed 29 Sept 2019.

PAME (Protection of the Arctic Marine Environment). (2018). Ships in the Polar Code area 2017. Akureyri: PAME Secretariat.

Parsons, K. (2014). Human thermal environments: The effects of hot, moderate, and cold environments on human health, comfort, and performance (3rd ed.). London/New York: CRC Press.

Pincus, R. (2015). Large-scale disaster response in the Arctic: Are we ready? Lessons from the literature on wicked policy problems. In Arctic Yearbook 2015. https://arcticyearbook.com/ arctic-yearbook/2015/2015-scholarly-papers/133-large\%20scale-disaster-response-in-thearctic-are-we-ready-lessons-from-the-literature-on-wicked-policy-problems. Accessed 4 July 2019.

Polar Code. (2014/2015). International Code for Ships Operating in Polar Waters (Polar Code), IMO Resolution MSC.385(94) (21 November 2014, effective 1 January 2017); Amendments to the International Convention for the Safety of Life at Sea 1974, IMO Resolution MSC.386(94) (21 November 2014, effective 1 January 2017); Amendments to MARPOL Annexes I, II, IV and V, IMO Resolution MEPC.265(68) (15 May 2015, effective 1 January 2017). http://www. imo.org/en/MediaCentre/HotTopics/polar/Documents/POLAR\%20CODE\%20TEXT\%20 AS\%20ADOPTED.pdf. Accessed 17 Oct 2019.

Schröder-Hinrichs, J.-U. (2018). The IMO framework and process of shipping regulation. Presented at the Contemporary and Emerging Challenges of Shipping in the Northwest Atlantic and Eastern Arctic Gateway Workshop, Dalhousie University, Halifax, Canada, 31 August. 
Schröder-Hinrichs, J.-U., Nilsson, H., \& Pålsson, J. (2013). Sustainable ocean development in the Arctic: Making a case for marine spatial planning in offshore oil and gas exploration. Ocean Yearbook, 27, 503-530.

SEDNA. (n.d.). Risk-based design framework. BMT Group Ltd. https://www.sedna-project.eu/ about/innovations/risk-based-design-framework/. Accessed 4 July 2019.

Sillitoe, A., Upcraft, D., Rich, K., LaRoche, M., Rø, B., \& Huse, J. (2010). Supporting human performance in ice and cold conditions. London: Lloyd's Register.

Snider, D., \& Jamieson, R. (2015). Ice classified marine vessels for Arctic operations (Paper $\# 7-12)$. Working document of the NPC Study: Arctic potential: Realizing the promise of US Arctic oil and gas resources. Washington, DC: National Petroleum Council.

SOLAS. (1974). International Convention for the Safety of Life at Sea, 1974 as amended (1 November 1974, entered into force 25 May 1980), 1184 UNTS 278.

Struzik, E. (2018). In the melting Arctic, a harrowing account from a stranded ship. YaleEnvironment360, 29 August. https://e360.yale.edu/features/in-the-melting-arcticharrowing-account-from-a-stranded-ship. Accessed 4 July 2019.

Sun, Z. (2018). International regulation of polar shipping: Polar Code and further development. In Climate change and the law of the sea: Adapting the law of the sea to address the challenges of climate change, Singapore, 13-14 March 2018. Singapore: Centre for International Law, National University of Singapore.

The Pew Charitable Trusts. (2016). The Integrated Arctic Corridors Framework: Planning for responsible shipping in Canada's Arctic waters. Philadelphia: The Pew Charitable Trusts.

Transport Canada. (2011). Winter navigation on the River and Gulf of St. Lawrence: Practical notebook for marine engineers and deck officers. TP 14335E. Quebec: Transport Canada.

UK HSE (United Kingdom Health and Safety Executive). (1972). The Robens Report. http://www. hse.gov.uk/aboutus/40/robens-report.htm. Accessed 4 July 2019.

UNCLOS. (1982). United Nations Convention on the Law of the Sea (10 December 1982, entered into force 16 November 1994), 1833 UNTS 3.

Waldholz, R. (2016). Is the Arctic ready for the Crystal Serenity? Alaska Public Media., 19 August. https://www.alaskapublic.org/2016/08/19/is-the-arctic-ready-for-the-crystal-serenity/. Accessed 4 July 2019.

Zhang, M. Y., Zhang, D., Yan, X. P., Goerlandt, F., \& Kujala, P. (2018). Collision risk factors analysis model for icebreaker assistance in ice-covered waters. In P. Kujala \& L. Lu (Eds.), Marine Design XIII (2) (pp. 659-668). Balkema: CRC Press.

Open Access This chapter is licensed under the terms of the Creative Commons Attribution 4.0 International License (http://creativecommons.org/licenses/by/4.0/), which permits use, sharing, adaptation, distribution and reproduction in any medium or format, as long as you give appropriate credit to the original author(s) and the source, provide a link to the Creative Commons license and indicate if changes were made.

The images or other third party material in this chapter are included in the chapter's Creative Commons license, unless indicated otherwise in a credit line to the material. If material is not included in the chapter's Creative Commons license and your intended use is not permitted by statutory regulation or exceeds the permitted use, you will need to obtain permission directly from the copyright holder. 